\title{
Synergistic Photodynamic and Photothermal Antibacterial Therapy Based on Conjugated Polymer Nanoparticles Doped Hydrogel
}

Qifan Cuit, Hongbo Yuan $\neq$, Xueying Bao $\neq$, Gang Mat, Manman Wü, Chengfen Xing $* \neq$

†School of Chemical Engineering, Hebei University of Technology, Tianjin 300401, China

$\ddagger$ Institute of Biophysics, Hebei University of Technology, Tianjin 300401, China

Corresponding Author *E-mail: xingc@hebut.edu.cn 


\section{a}

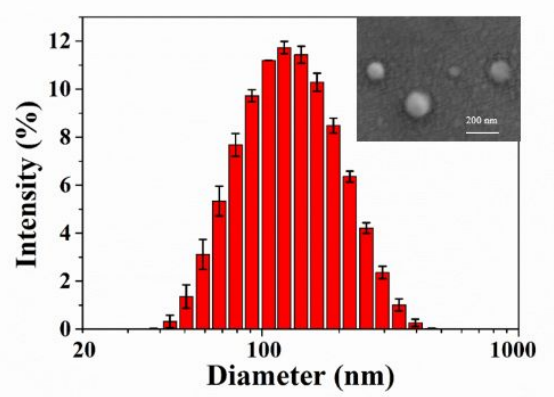

b

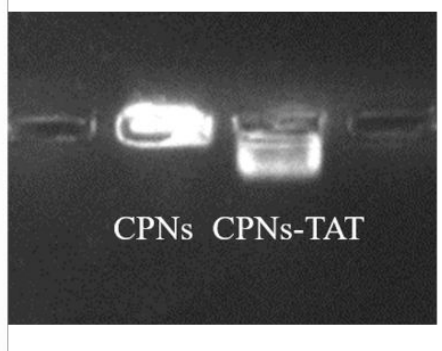

C

\begin{tabular}{|c|c|}
\hline & $\zeta$ Potential $(\mathrm{mV})$ \\
\hline CPNs & $-24.8 \pm 2.0$ \\
\hline CPNs-TAT & $29.7 \pm 1.8$ \\
\hline
\end{tabular}

Figure S1 (a) Size distribution histograms of dynamic light scattering analysis of CPNs-TAT. Error bars are standard deviations from three independent experiments. The illustration in the upper right corner shows the SEM image of the nanoparticles. (b) Agarose gel electrophoresis of CPNs before and after grafting TAT. (c) $\zeta$ potential of CPNs before and after TAT covalent connection.

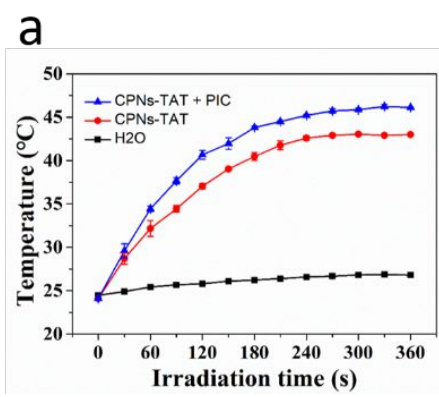

b

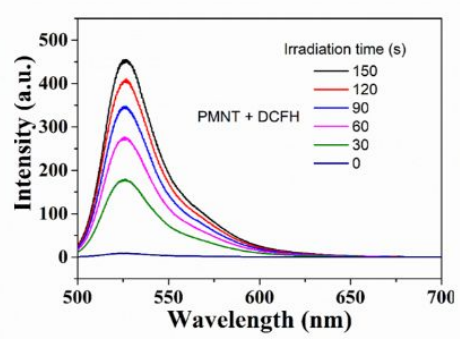

C

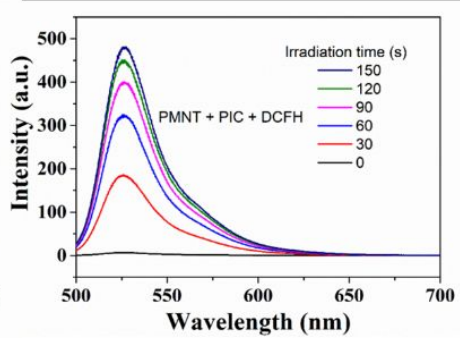

Figure S2. (a) The photothermal heating curve of CPNs-TAT in the presence and absence of PIC.

(b) The fluorescence spectrum of PMNT oxidized DCFH; (c) Fluorescence spectra of PMNT oxidized DCFH in the presence of PIC. The irradiation time is $0-150 \mathrm{~s}$ and the excitation wavelength is $488 \mathrm{~nm},[\mathrm{PMNT}]=0.17 \mu \mathrm{g} \mathrm{mL}^{-1}$, $[\mathrm{DCFH}]=40.0 \mu \mathrm{M},[\mathrm{PIC}]=0.5 \mathrm{mg} \mathrm{mL}^{-1}$.
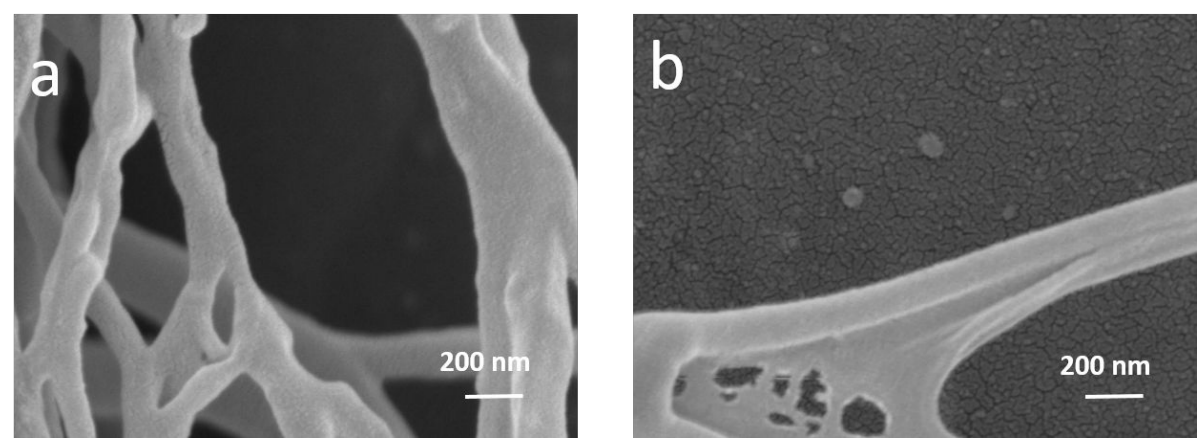
Figure S3. SEM images of (a) PIC hydrogel; (b) PIC hydrogel with CPNs-TAT were observed at an accelerating voltage of $5.0 \mathrm{kV}$.

a

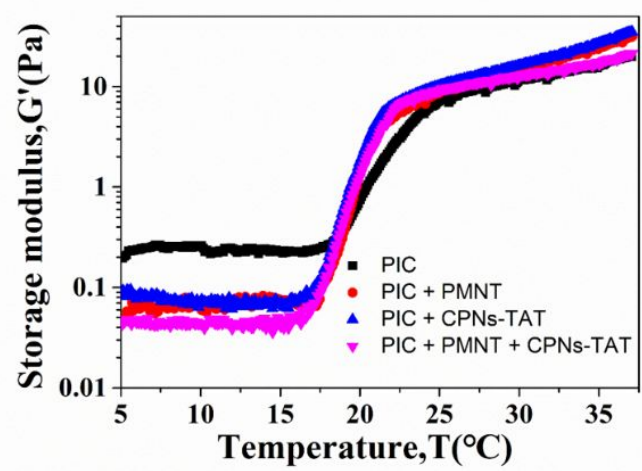

b

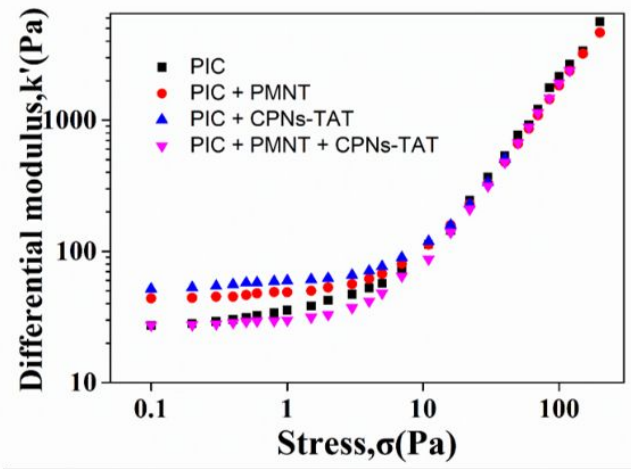

Figure S4. (a) Storage modulus $\mathrm{G}^{\prime}$ as a function of temperature $\mathrm{T}$ as for PIC hydrogel in the presence or absence of PMNT and CPNs-TAT. (b) Differential modulus K' as a function of stress $\sigma$ for PIC hydrogel in the presence or absence of PMNT and CPNs-TAT. [PIC] $=1 \mathrm{mg} \mathrm{mL}^{-1},[\mathrm{PMNT}]$ $=0.66 \mu \mathrm{g} \mathrm{mL} L^{-1},[\mathrm{PDPP}]=10 \mu \mathrm{g} \mathrm{mL} \mathrm{m}^{-1}$.

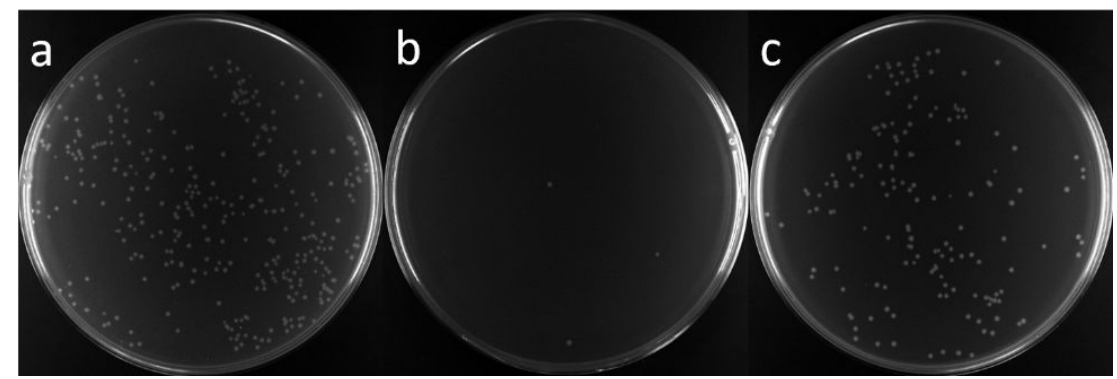

Figure S5. (a) Blank control, (b) Cfu of E. coli suspension incubated with PIC hybrid ([PIC] $=0.5$ $\left.\mathrm{mg} \mathrm{mL}-1,[\mathrm{PMNT}]=2.65 \mu \mathrm{g} \mathrm{mL}^{-1},[\mathrm{PDPP}]=15 \mu \mathrm{g} \mathrm{mL}^{-1}\right)$ and exposured to white $\left(30 \mathrm{~mW} \mathrm{~cm}^{-2}, 10\right.$ mins) and NIR light ( $\left.0.7 \mathrm{~W} \mathrm{~cm}^{-2}, 5 \mathrm{mins}\right)$, respectively. (c) Cfu of E. coli suspension incubated with $\mathrm{HP}\left([\mathrm{HP}]=20 \mu \mathrm{g} \mathrm{mL}^{-1}\right)$ and exposured to white light $\left(30 \mathrm{~mW} \mathrm{~cm}^{-2}, 15 \mathrm{mins}\right)$ 


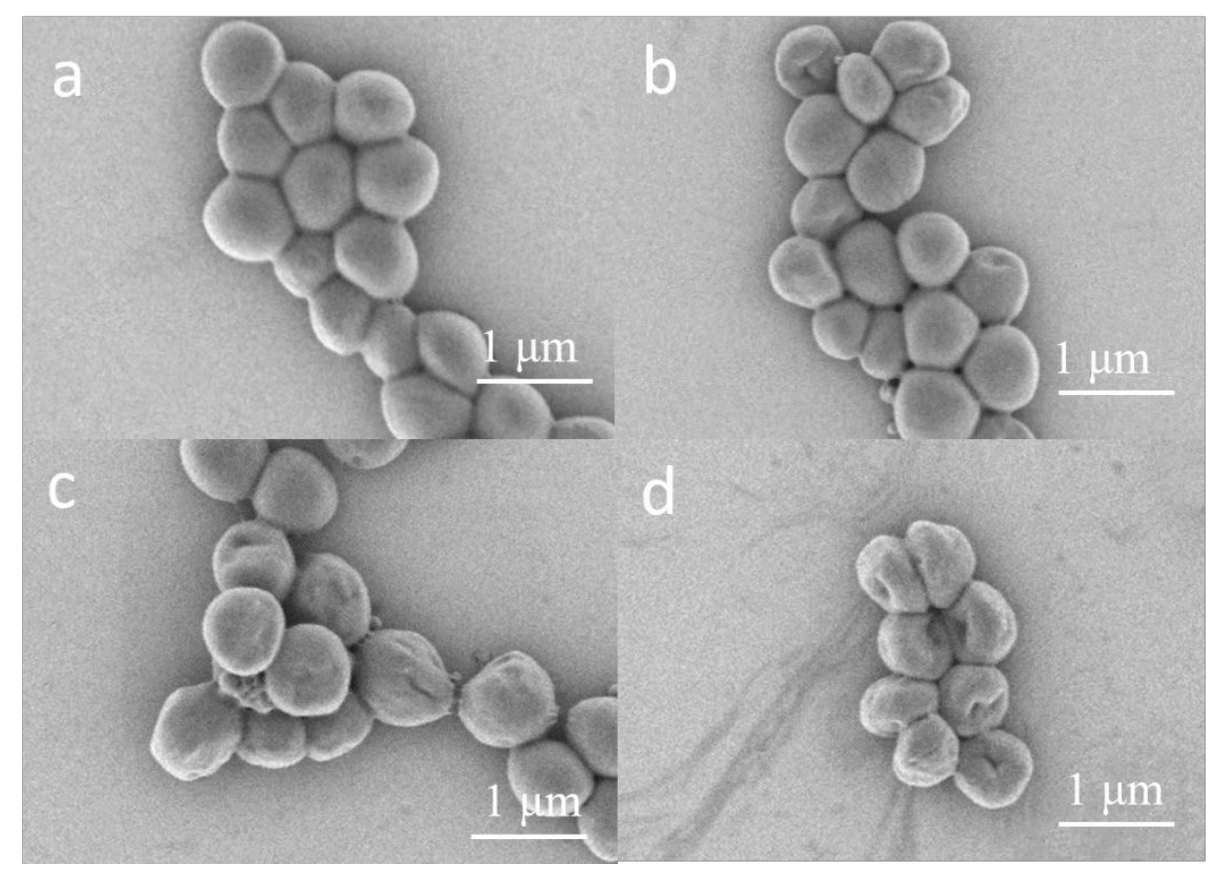

Figure S6. SEM images of $S$. aureus after different treatments. (a) SEM images of $S$. aureus incubated with PIC hydrogel without any light irradiation; (b) SEM images of S. aureus incubated with PIC/CPNs-TAT complex without any light irradiation; (c) SEM images of S. aureus incubated with PIC/PMNT complex with white light irradiation; (d) SEM images of S. aureus incubated with PIC hybrid with white light and NIR light irradiation.
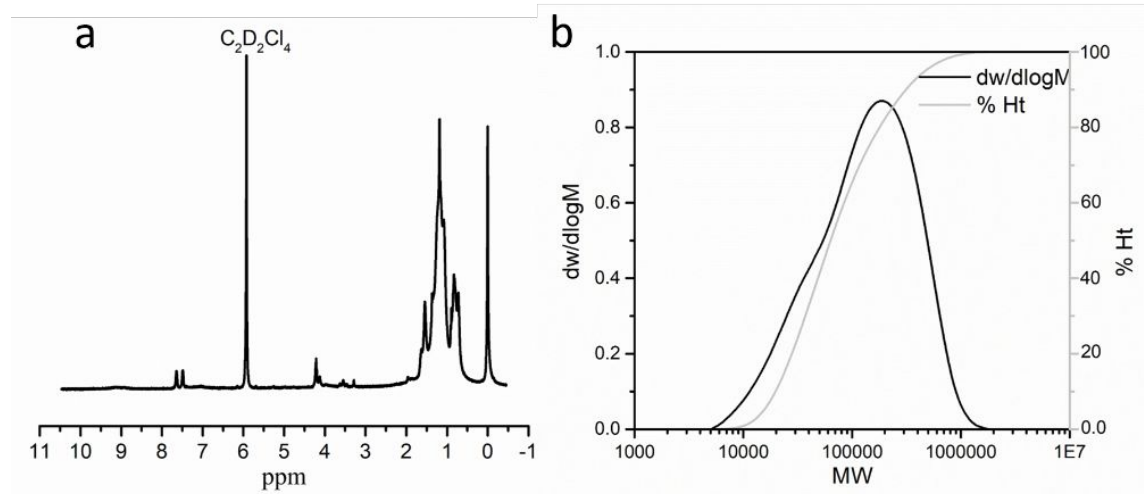

Figure S7. (a) ${ }^{1} \mathrm{H}-\mathrm{NMR}$ characterization of PDPP. (b) GPC characterization of PDPP. 


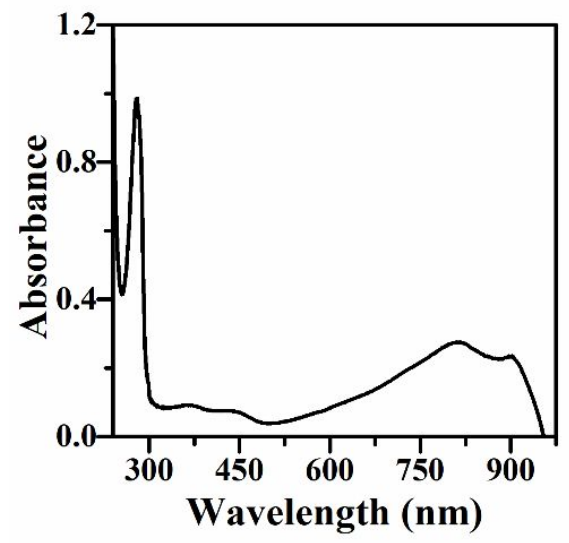

Figure S8. The absorption spectra of PDPP $\left(24.0 \mu \mathrm{g} \mathrm{mL}^{-1}\right)$ in aqueous solutions. 